\title{
LOS MANUSCRITOS GRIEGOS DEL CARDENAL ZELADA: UNA BIBLIOTECA ROMANA EN LA CATEDRAL DE TOLEDO*
}

\author{
INMACULADA PÉREZ MARTÍN
}

Los manuscritos griegos del Archivo y Biblioteca Capitulares de Toledo sólo fueron objeto de un somero inventario por parte de Charles Graux y André Martin ${ }^{1}$ y todavía no han sido descritos según criterios de catalogación modernos, labor que pretendemos realizar en un futuro próximo. Aunque en Toledo desde época visigoda circularían textos griegos y, por supuesto, en el siglo XVI, la etapa dorada del helenismo toledano, se copiaron y estudiaron manuscritos en esta lengua ${ }^{2}$, ningún códice -hasta donde sabemos-fue custodiado por la Catedral ${ }^{3}$. En general,

\footnotetext{
* Quiero agradecer a D. José Luis García, archivero del obispado de Cartagena, quien ha recogido una documentación riquísima sobre los orígenes murcianos de Francesco Xaverio de Zelada, el haberme guiado por el intrincado y apasionante mundo de los archivos españoles e italianos. Mi agradecimiento ha de extenderse a D. Ángel Fernández Collado, director del Archivo y Biblioteca Capitulares de Toledo, quien amablemente auspicia nuestro catálogo de los códices e impresos griegos de la mencionada Biblioteca.

Los documentos mencionados aquí pertenecen a los siguientes archivos: ASR = Archivio di Stato di Roma; ASV = Archivio Segreto Vaticano; AEESS = Archivo de la Embajada de España ante la Santa Sede.

1. Ch. Graux - A. Martin, "Rapport sur une mission en Espagne et en Portugal. Notices sommaires des manuscrits grecs d'Espagne et de Portugal", Nouvelles Archives des Missions scientifiques et littéraires, 2 (1892), pp. 1-322: 229-298.

2. Sobre la copia de manuscritos griegos en Toledo, G. de Andrés, Helenistas del Renacimiento en Toledo: el copista cretense Antonio Calosinás, Toledo, Instituto Provincial de Investigaciones y Estudios Toledanos, 1999.

3. Sobre el fondo antiguo de la Biblioteca Capitular y los distintos inventarios, vid. J. Foradada, "Reseña histórica de la Biblioteca del Cabildo de la Catedral de Toledo", Revista de Archivos, Bibliotecas y Museos, 7 (1877), fasc. 4, pp. 49-54 y fasc. 5, pp. 65-69; J. Janini - R. Gonzálvez - A. M. Mundó, Catálogo de los manuscritos litúrgicos de la Catedral de Toledo (Publicaciones del Instituto Provincial de Investigaciones y Estudios Toledanos, ser. III, Estudios, catálogos, repertorios 11), Toledo 1977, pp. 11-16; R. Gonzálvez Ruiz, "Evolución histórica de la Biblioteca Capitular de Toledo", en Coleccionismo y bibliotecas (siglos XV y XVIII), M. ${ }^{a}$ L. López-Vidriero - P. M. Cátedra (dir.), M. ${ }^{a}$ I. Hernández González (ed.), Salamanca 1998, pp. 235-256. En la Memoria de los libros que están en la librería de la Sta. Yglesia de Toledo, conservada en San Lorenzo de El Escorial, Biblioteca del Real
} 
los que poseían en Toledo Juan de Vergara, Alvar Gómez de Castro y Antonio de Covarrubias fueron adquiridos por Luis de Castilla y entraron en 1656 en el Monasterio de San Lorenzo de El Escorial con la biblioteca del Conde-Duque de Olivares ${ }^{4}$.

\section{La donación de Zelada}

Para encontrar en la Biblioteca Capitular manuscritos griegos, hay que esperar, por lo tanto, a la donación del Cardenal Francesco Saverio (o Xaverio, en la grafía de la época) de Zelada en 1798-995. De su biblioteca, que constaba de unos 1.540 códices $^{6}$, de los que 45 eran total o parcialmente en griego ${ }^{7}$, disponemos de la valiosa descripción contemporánea que el jesuita valenciano Juan Andrés, que visitó Roma en 1785, incluyó en las cartas enviadas a su hermano Carlos y publicadas por éste al año siguiente. Andrés describe en detalle la residencia del Cardenal, que se suele localizar en Palazzo Margani (Paganica) Conti ${ }^{8}$, pero refiramos tan sólo el

Monasterio L.I.13, ff. 107-133v, se menciona un «Crisóstomo en griego» (f. 133v) que puede ser el Toledo, ABC 25-11, editado en Basilea 1529. El Index librorum de 1591 (Madrid, Biblioteca Nacional 13830, ff. 77-78v) reseña 49 libros griegos, todos ellos impresos; los índices de 1727 (Matrit. 13413) no indican la lengua en que muchos libros están escritos ni definen como grupo aparte los griegos, de modo que no es posible distinguir los textos griegos de sus traducciones.

4. G. de Andrés, "El Arcediano de Cuenca D. Luis de Castilla († 1618) protector del Greco y su biblioteca manuscrita", Hispania Sacra, 35 (1983), pp. 87-141. No todos los manuscritos de estos humanistas se encuentran en El Escorial, también en la Biblioteca Nacional de Madrid. Sobre las bibliotecas humanistas en Toledo, G. de Andrés, "El helenismo del canónigo toledano Antonio de Covarrubias: un capítulo del humanismo en Toledo en el siglo XVI", Hispania Sacra, 40 (1988), pp. 237-313; P. M. Cátedra, "La biblioteca de la Universidad de Toledo (siglo XVI)”, Bulletin of Spanish Studies, 81 (2004), pp. 927-956; I. Pérez Martín, Las bibliotecas del doctor Juan de Vergara y de Alfonso de Cortona (Supplementa Mediterranea 10), Málaga 2008, pp. 52-55.

5. En la bibliografía al uso, la fecha de la llegada de los códices de Zelada a Toledo fluctúa entre 1797 y 1801 ; sólo R. Gonzálvez en J. Janini - R. Gonzálvez - A. M. Mundó, Catálogo (cit. n. 3), pp. 52-53, ofrece las fechas correctas. Tampoco es raro encontrar los términos "adquisición" o "compra" en vez del correcto "donación" de los libros ni la mención de Lorenzana como donante o adquisidor de la biblioteca de Zelada. Las Actas del Cabildo del 27 de julio de 1799 proporcionan una información clara y fiable sobre la llegada de los códices a Toledo, producida poco antes de la reunión del Cabildo de ese día. La donación de Zelada y el envío de la biblioteca habían sido anunciados por el arzobispo Lorenzana desde Florencia el 19 de mayo de 1798 en carta al Cabildo toledano, pero no hubo adquisición previa por su parte.

6. La cifra en J. Foradada, "Reseña histórica" (cit. n. 3), p. 66.

7. En Toledo recibieron las siguientes signaturas: 8-22, 9-14, 9-20, 9-32, 9-40, 17-26 (ausente en Graux Martin), 31-30, 31-31, 31-32, 31-33, 45-30, 49-21, 51-5, 88-22, 94-12, 94-23, 94-24, 95-8, 96-34, 96-37, 98-13, 98-14, 99-16, 99-44, 100-2, 100-3, 100-4, 100-5, 101-13, 101-15, 101-16, 102-33, 102-34, 119-21. A éstos hay que añadir una selección de los códices de Toledo custodiados desde 1869 en la Biblioteca Nacional de Madrid: Res/235 (olim Toledo, ABC 1-12), Vitr/26-4 (2-10), Mss/4.694 (31-28), Vitr/26-5 (31-29), Mss/4.855 (34-37), Vitr/26-1 (97-15), Mss/4.590 (100-1), Mss/4.817 (101-12), Mss/4.809 (101-14), Mss/4.808 (102-35) y 10.096 (103-4).

8. Vid. A. de Angelis, "La collezione dei primitivi del cardinale Francesco Saverio de Zelada (1717-1801)", Ricerche di Storia dell'arte, 77 (2002) [= La scoperta dei primitivi fra Sette e Ottocento], pp. 41-54: 42. Palazzo 
pasaje relativo a la biblioteca: «La escalera (de la mansión de Zelada) es un museo lapidario, por estar toda ella llena de lápidas griegas y romanas; y llegando a la vastisima librería se ven cinco o seis salas todas llenas de libros, algunos raros, otros preciosos por alguna circunstancia particular y los más muy buenos y magistrales en sus clases, que todas las abraza aquella biblioteca. En dos salas se encierran manuscritos antiguos y modernos, entre los quales además de muchos preciosos por lo que contienen, hay otros recomendables por lo raros, como son un Salterio en lengua siríaca de láminas de bronce, otro libro de corteza de árbol, un rótulo de piel de toro, algunos de miniaturas singulares, y otros de alguna otra raridad. ${ }^{9}$ »

Junto con la colección Zelada, llegaron a Toledo, como parte de una treintena de códices litúrgicos de lujosa factura pertenecientes a la Sacristía pontificia, dos códices griegos más ${ }^{10}$, los Toledo, ABC 38-21 y 38-22"11, ambos con la siguiente nota que indica que fueron "salvados del desastre" de la Repubblica Romana por Lorenzana: Anno 1798. Codex est MS. magna cura pretioque maxima in Urbis disreptione redemptur S. Ecclesia Toletance dono datus a suo Praesule Card.le de Lorenzana. La Sacristía había sido saqueada por las tropas napoleónicas y Lorenzana pudo adquirir los códices poco después en el mercado de antigüedades que los desmanes de la ocupación activaron ${ }^{12}$.

La mencionada nota fue incluida por el prior del convento de los Agustinos, Lorenzo Frías, el encargado de confeccionar un nuevo inventario de la biblioteca capitular desde finales de $1800^{13}$. Frías catalogó en primer lugar el fondo Zelada y a continuación los restantes libros,

Margani Conti se encuentra en via Aracoeli, 13, en la esquina con Botteghe Oscure, frente a Palazzo Astalli, pero habría que revisar más exhaustivamente de lo que lo hemos hecho la documentación del ASV para confirmar que éste fue realmente la última residencia de Zelada y para averiguar desde cuándo lo fue.

9. Cartas familiares del abate D. Juan Andres a su hermano D. Carlos Andres, dándole noticia del viage que hizo a varias ciudades de Italia en el año 1785, publicadas por el mismo D. Carlos, 2 vols., Madrid 1786, I, pp. 185-186. Un resumen del texto en A. Lo Vasco, Le biblioteche d'Italia nella seconda metà del secolo XVIII dalle “Cartas familiares” dell' Abate Andres, Milano 1940, pp. 67-68.

10. Se trata de los libros pontificales y litúrgicos usados por Urbano VIII procedentes de la sacristía de la Capilla Sixtina; vid. E. De Laurentiis, "Il Cardinale Lorenzana e i codici liturgici della Sacrestia Sistina a Toledo", El cardenal Lorenzana, arzobispo de Toledo. Ciclo de conferencias en el II centenario de su muerte (1804-2004), A. Fernández Collado (coord.), Toledo, Instituto Superior de Estudios Teológicos San Ildefonso, 2004, pp. 265-301; Ead., "Nuove miniature nei codici della Sacrestia Sistina a Toledo", Perino del Vaga, prima, durante, dopo. Atti delle Giornate Internazionali di Studio. Genova 26-27 maggio 2001, Genova, De Ferrari, 2004, pp. 78-95.

11. Sobre el contenido de estos códices misceláneos, vid. Ch. Graux - A. Martin, "Rapport" (cit. n. 1), pp. 261-263.

12. E. De Laurentiis, "Il Cardinale Lorenzana" (cit. n. 10), p. 266, n. 4, refiere el testimonio contemporáneo de P. Baldassarri, Relazioni delle avversità e patimenti del glorioso papa Pio VI negli ultimi tre anni del suo pontificato, II, Modena 1840-43, p. 346: «Ed alla sagrestia delle Cappelle Pontificali non solamente tolsero tutti li vasi ed arredi d'oro e d'argento, ed i messali scritti benissimo ed ornati d'eccellenti miniature...».

13. Vid. L. Sierra Nava-Lasa, "Los archivos de Toledo con referencia al cardenal Francisco Antonio de Lorenzana (1754-1800)", Homenaje a Don Agustín Millares Carlo, I, Gran Canaria, Caja Insular de Ahorro, 1975, pp. 661-684: 663; J. Janini - R. Gonzálvez - A. M. Mundó, Catálogo (cit. n. 3), Toledo 1977, p. 11. Vid. L. Frías, "Breve noticia de los manuscritos de la Biblioteca de la Santa Iglesia de Toledo, escrita por el Padre Maestro Fr. Lorenzo Frías, 
hasta completar un somero inventario de 2.458 manuscritos y 905 volúmenes impresos en 1808 . Fue un trabajo difícil para alguien que sólo debía de estar familiarizado con libros españoles y el máximo del celo desplegado en los códices griegos fue incluir alguna nota al inicio del volumen, como en el Toledo, ABC 96-34, donde consigna la traducción latina del comienzo de los Pneumatika de Herón (Pl. 4). El texto griego fue copiado por Emanuel Provataris en Roma entre 1557 y $1570^{14}$.

El mayor escollo que encontró Frías fueron las lenguas orientales (griego, siríaco, árabe, hebreo y chino) en las que estaban escritos «los preciosos manuscritos que dicho Señor Em.mo (Zelada) había recogido en su larga y brillante carrera, entre los cuales hay muchos códices escritos en lenguas orientales, de los que ninguna inteligencia hay en estos países» (Actas capitulares del 1 de febrero de 1802). El Cabildo se informa entonces de que el antiguo bibliotecario del Cardenal, Angelo Battaglini, «tiene en su poder escritas y apuntadas todas las noticias concernientes a los expresados códices, de los cuales podrá formarse un índice del contenido de todos los latinos, italianos, franceses y españoles, porque de los demás, que son pocos griegos, árabes, chinos y de otras lenguas exóticas, nada hay trabajado y únicamente se encuentra en ellos una nota de lo que contienen (ibidem)». Son malas noticias, y el Cabildo no se decide a pagar los 150 pesos que Battaglini pide por un catálogo más preciso y detallado que el que Frías pudo acabar en 1804, quizá porque justamente no incluía la descripción de los escritos en lenguas "raras" 15 . Pero Battaglini hizo el trabajo y su inventario de los códices de Zelada (redactado cuando ya no tenía los manuscritos a su disposición) permaneció entre sus papeles, que son custodiados ahora en la Biblioteca Universitaria de Bologna e incluyen también notas y extractos sobre la biblioteca de Zelada. El Latinorum Italorum Gallorum Hispanorumque manuscriptorum codicum Zeladianae Bibliothecae catalogus lleva la cota Bonon. $4256^{16}$ y en el Monitum que precede el catálogo (I, f. III), Battaglini alude a esta petición del Cabildo: «Hebraeorum, Graecorum, Arabicorum, Sinensiumque examen egregiis viris persaepe fuit demandatum; quid

pocos días antes de su muerte y enviada a un amigo suyo”, en M. Salvá - P. Sainz de Baranda (ed.), Colección de Documentos inéditos para la Historia de España, IX, Madrid 1846, pp. 566-574. Al parecer fue Lorenzana quien designó a Frías como la persona adecuada para la labor aunque, al dejar el arzobispado en 1800, fue su sucesor Luis de Borbón quien facilitaría el proceso de catalogación.

14. Puesto que la escritura es la del período 3b señalado por P. Canart, "Les manuscrits copiés par Emmanuel Provataris (1546-1570). Essai d'étude codicologique”, Mélanges Eugène Tisserant, VI (Studi e Testi 236), Città del Vaticano 1964, pp. 173-287: 198. La identificación es nuestra.

15. El problema se solucionó en lo relativo a los códices hebreos gracias al secretario de Lorenzana, Sebastián Pascual, que desde Roma envió al Cabildo en 1816 los índices, que había comprado «a un criado de su Emia. el Dr. Zelada, que los havia guardado, quando se llevaron a Toledo los Códices» (Matrit. 7116); cit. por J. M. Millás Vallicrosa, "Manuscritos hebraicos de la Biblioteca Capitular de Toledo", Al-Andalus. Revista de las Escuelas de Estudios Árabes de Madrid y Granada, 2 (1934), pp. 395-430: 396.

16. A. Campana, "Battaglini Angelo", Dizionario biografico degli Italiani, VII, Roma 1965, pp. 222-225: 223; S. Lilla, I manoscritti Vaticani Greci. Lineamenti di una storia del fondo (Studi e Testi 415), Città del Vaticano 2004, pp. 79-83. El Bonon. 4256 consta de 2 vols. con 1.558 pp. en total, de las que han desaparecido las 140 primeras. 
ipsi egerint, ignotum. Latinorum, Italorum, Gallorum, Hispanorumque, quorum copia in dies augebatur, catalogum opportunis et eruditis adnotationibus illustrandum pro sua benevolentia a me petiit.» $\mathrm{Al}$ final del catálogo, Battaglini tiene a bien precisar en un Avvertimento la necesidad de distinguir entre los códices de Zelada y del Vaticano: «Se alcun'altro manoscritto oltre i sopra indicati da taluno, che dasse relazione de' Codici già Zeladiani, ed ora Capitolari Toletani, venisse enunciato come già spettante all'Emo. e Rmo. Cardinal de Zelada, non devesi credere. Devesi dire più tosto della Biblioteca Vaticana ${ }^{17}$.».

Todos los códices de Zelada llevan en una hoja de guarda inicial la signatura que Frías les dio al llegar a Toledo (Cajon $x$ Num. $x$ ) seguida del nombre subrayado: Zelada ${ }^{18}$. La doble cifra se repite en un papel pegado sobre el lomo de una encuadernación romana que en muchos casos es contemporánea de Zelada y constituye una evidente marca externa de procedencia. Estas encuadernaciones fueron realizadas en el propio palacio romano del Cardenal, por un cameriere suyo, Domenico Frediani ${ }^{19}$, en piel roja o marrón sobre cartón, con sencillos adornos florales y estrellas dorados en las tapas y el lomo. Es en el lomo donde se exhibe en dorado el título abreviado en mayúsculas y, en la parte inferior, el emblema de Zelada: un árbol con la celada en la copa y las siglas a ambos lados del tronco: $F$ (rancesco) X(averio) de Zelada ${ }^{20}$.

En unos casos contados se mantuvo la encuadernación antigua: la del Toledo, ABC 96-3721, que conserva su encuadernación cretense original, o el Toledo, ABC 45-30, en piel roja sobre tabla, que podría ser contemporánea del códice (Esteban de Bizancio, De civitatibus), copiado en Florencia en 1496 por Miguel Suliardo (PI. 2) ${ }^{22}$. También parece ser de comienzos del siglo XVI, como el volumen que protege, la encuadernación renacentista sobre tabla del Matrit.

17. Bonon. 4256, II, pp. 681-682. Sobre el conflicto creado en la Biblioteca Vaticana por el envío de los códices de Zelada a Toledo, vid. infra, pp. 582-583.

18. Muchos de los manuscritos griegos de Zelada llevan en las guardas iniciales una pequeña cifra árabe, que corresponde a una ordenación original ya detectada por G. Mercati, Note per la storia di alcune biblioteche romane nei secoli XVI-XIX (Studi e Testi 164), Città del Vaticano 1952, pp. 78-79. Todas las signaturas antiguas están comprendidas entre el nr. 51 y el nr. 106 y, por lo tanto, responden a una ordenación común a los códices en otras lenguas. Como es obvio, los dos códices griegos donados por Lorenzana que compartieron el envío de 1799 llevan el mismo número de orden sin la indicación zeladiana. G. Mercati, ibidem, p. 79, que sólo conoce los códices de Toledo por la descripción de Graux - Martin, señala que el 100-5 no pertenece a Zelada, pero en el f. 1 se lee la habitual indicación: Cajon 100. Num. 5 Zelada.

19. Así lo indica Zelada en su testamento, conservado en el ASR, Notai, Auditor Camerae, vol. 5.509, ff. 1330-1343, 1366-76: «Essendomi sempre prevalsuto per legare li miei Protocolli, e Libri di Domenico Frediani mio Cameriere, lascio al d.o Domenico tutti gli attrezzi, cioè Tavolone, Torchio, ferri, e tutt'altro appartenente all'Officio di Legatore.»

20. Un ejemplo de encuadernación zeladiana en M. Sánchez Mariana, Bibliófilos españoles. Desde sus orígenes hasta los albores del siglo XX, Madrid 1993, pp. 224-225 (Matrit. 5455).

21. Ch. Graux - A. Martin, "Rapport" (cit. n. 1), pp. 272-273.

22. Ch. Graux - A. Martin, "Rapport" (cit. n. 1), pp. 263-264; Stephani Byzantii Ethnica, I, Alpha-Gamma (Corpus Fontium Historiae Byzantinae 43/1), M. Billerbeck (rec.), Berlin, Walter de Gruyter, 2006, p. 9* y n. 13. 
10096 (olim Toledo, ABC 103-4), restaurada por encargo de Zelada con un error de inversión de las tapas.

Tanto la antigua signatura toledana como la encuadernación con el escudo de Zelada fueron respetadas en la Biblioteca Nacional, donde, en 1869, obedeciendo al «Decreto de Incautación» del Ministro de Fomento de la I República, Manuel Ruiz Zorrilla, se llevó una selección de códices toledanos que afectó a once griegos, destacables por su antigüedad, su texto o su valor $\operatorname{artístico~}^{23}$. Una de las encuadernaciones zeladianas preservadas, la del Matrit. Res/235, es especialmente lujosa (PI. 3), en justa correspondencia con el valor de este Evangelio con catena de comienzos del siglo X, el códice griego más antiguo de la biblioteca de Zelada ${ }^{24}$.

Zelada tomó la decisión de donar a la Catedral de Toledo su biblioteca manuscrita en Florencia, donde se había instalado con la mayor parte de la Curia pontificia. Escenificando el episodio más dramático de la ocupación napoleónica de los Estados Pontificios, los Cardenales habían salido de Roma en febrero de 1798 junto al papa Pío VI, pero fueron separados del pontífice, retenido en Siena. Entre ellos, con la misión de hacer llegar a Pío VI la ayuda española, se encontraba el Cardenal Lorenzana, que consigue sólo esporádicamente permiso para estar al lado del papa ${ }^{25}$.

Las relaciones de Zelada con los representantes del rey de España en Roma siempre habían sido intensas, como veremos, pero las tristes circunstancias del exilio estrecharon sin duda los lazos con Lorenzana, con quien el Cardenal tendría muchas ocasiones de departir sobre lo que les depararía el futuro ${ }^{26}$ y preparar el destierro en España al que parecía destinado por los

23. Cf. supra n. 7. La correspondencia de las antiguas signaturas toledanas con las actuales de la Biblioteca Nacional, en I. R. Vieillefond, "Complemento al Catálogo de manuscritos griegos de la Biblioteca Nacional de Madrid”, Emerita, 3 (1935), pp. 193-213. El inventario parcial realizado por Octavio de Toledo con ocasión de la incautación fue editado mucho más tarde: J. M. ${ }^{a}$ Octavio de Toledo, Catálogo de la librería del Cabildo de Toledo (Biblioteca de la Revista de Archivos, Bibliotecas y Museos 3), I, Manuscritos, Madrid 1903; II, Impresos, Madrid 1906. Cf. M. Sánchez Mariana, "Don José María Octavio de Toledo o treinta y cinco años de historia de la Biblioteca Nacional”, Boletín de la ANABAD, 42.1 (1992), pp. 59-97.

24. Vid. la ficha correspondiente de I. Pérez Martín en Lecturas de Bizancio. El legado escrito de Grecia en España. Catálogo de la Exposición, M. Cortés Arrese - I. Pérez Martín (com.), Madrid, Biblioteca Nacional - Ministerio de Cultura, 2008, pp. 48-49 (nr. 2). El emblema de Zelada ocupa aquí la parte central de las tapas en piel marrón y verde, profusamente decorada con motivos vegetales y círculos dorados.

25. Lorenzana viajó a Roma en 1797 como miembro de una embajada especial compuesta por tres arzobispos que debían tratar asuntos con la Santa Sede, en realidad una excusa para tenerlo lejos de la Corte, donde su presencia importunaba a Manuel de Godoy; vid. R. Olaechea, El cardenal Lorenzana en Italia, 1797-1804, León, Institución Fray Bernardino de Sahagún de la Excma. Diputación Provincial - CSIC, 1980, pp. 73-137, sobre la embajada, y pp. 99-112, sobre Lorenzana; A. Fernández Collado, "El cardenal Lorenzana: semblanza de un singular arzobispo de Toledo", El cardenal Lorenzana (cit. n. 10), pp. 9-26: 25. Lorenzana nunca volvió a España: en 1800 renunció al arzobispado de Toledo y cuatro años después falleció en Roma.

26. Despuig, representante real, menciona en su Libro de Viages que Zelada no se despegaba de Lorenzana en aquellas circunstancias; vid. R. Olaechea, El cardenal Lorenzana (cit. n. 25), pp. 242, 248, 256; H. Rodríguez de Gracia, "Francisco Antonio Lorenzana: un arzobispo viajero", El cardenal Lorenzana (cit. n. 10), pp. 179-216: 213. 
franceses ${ }^{27}$. La donación de su biblioteca manuscrita (que dejó en Roma $^{28}$, a diferencia de los cuadros y otros objetos de arte que llevó consigo a Florencia y cedió a Alessandro Rinuccini ${ }^{29}$ ) se explica así como un paso previo a la deportación y como un gesto de agradecimiento a Lorenzana, que era un apasionado bibliófilo cuyo interés por los libros estaba fuera de duda ${ }^{30}$ y que no dejaría de ponderar que en Toledo la biblioteca estaría a salvo ni de mencionar cómo había reformado la Biblioteca Capitular y creado la Biblioteca Arzobispal, cuyos fondos custodia

27. Según el embajador español ante la Santa Sede, José Nicolás de Azara, las últimas órdenes francesas recibidas en Siena son «que se destierre al Cardenal Zelada, gran Penitenciario, naturalizado español, de 81 años cumplidos y postrado en la cama por la hinchazón monstruosa de sus piernas que le anuncian pocos días más de vida.» (R. Olaechea, El cardenal Lorenzana [cit. n. 25], p. 157; cf. Id., Las relaciones hispano-romanas en la segunda mitad del XVIII. La Agencia de Preces, Zaragoza, Institución Fernando el Católico [CSIC], 1965 [reprod. facs. Zaragoza 1999, con prólogo de A. Mestre], II, p. 501 y n. 117). Zelada se recuperó, como implican sus siguientes movimientos: participa en el cónclave de Venecia desde julio de 1799 y vuelve a Roma, donde muere el 19 de diciembre de 1801 .

28. Así lo indica Battaglini, en el Bonon. 4256, p. 681: «sappiamo, che in tempo della democratica così detta Repubblica Romana, cioè nel 1798, assente il cardinal de Zelada e chi aveva la custodia della di lui libreria (sc. el propio Battaglini), molti volumi non suoi furono incassati, e mandati a Toledo.» Cf. el pasaje de las Effemeridi Letterarie di Roma, 1 (1820), p. 141, citado por G. Mercati, Note (cit. n. 18), p. 65, n. 1: los códices de Zelada estaban «già preparati per passare in dono parte al secreto Archivio Pontificio e parte alla Biblioteca Vaticana, nei funestissimi giorni della così detta Repubblica Romana con nuova risoluzione del Cardinale» debieron «essere trasportati alla Cattedrale arcivescovile di Toledo».

29. Cf. ASR, Notai, Auditor Camerae, vol. 5.509 (testamento de Zelada): «Prego inoltre il Sud(ett)o Sig(no)re Card. Rinuccini di gradire il titolo di Legato, ed in altro miglior modo tutti li Quadri si antichi, che moderni, che si troveranno presso di me, e che io intendo di lasciare a sua libera disposizione, niuno eccettuato, come pure tutte le mie Stampe poste in Quadri, e che tutto serva di unione a quelli Quadri, e Stampe, ch'io feci portare a Firenze, ed io regalai al Sig(no)re March(es)e Alessandro Rinuccini»; cf. f. 1369: «che avendo io fatto venire da Roma Stampe tanto legate in Libri, che poste in Cornici, Semplici, ed in qualunque maniera, come anche Quadri, Porcellane, Bronzi, ed altre cose, che ho date al Sig(no)re Marchese Alessandro Rinuccini». Entre los cuadros de Zelada destacan los retratos que de él pintó Rafael Mengs, hoy en el Art Institute de Chicago (PI. 1) y en el Museo Civico di Pestoia. Vid. S. Röttgen, "Two Portraits by Mengs in The Art Institute of Chicago", Art Institute of Chicago Museum Studies, 5 (1970), pp. 64-75; M. E. Micheli, "Naturalia e artificialia nelle raccolte del Cardinale Francesco Saverio de Zelada", en Atti del Convegno Internazionale "Iluminismo e Ilustración. Le antichità e i loro protagonisti in Spagna e in Italia nel XVIII secolo" (Roma 30 novembre-2 dicembre 2001) (Bibliotheca Italica 27), J. Beltrán Fortes - B. Cacciotti - X. Dupré - B. Palma (a c. di), Roma 2003, pp. 231-241.

30. Lorenzana preparó en México en 1770 una edición de las Historias de Nueva-España de Hernán Cortés; en España, la del Breviarum Gothicum, Madrid, Joaquín Ibarra, 1775, y las obras de S. Martino, Segovia, 1782-1786. Finalmente, patrocinó en Roma una nueva edición de S. Isidoro, que acabó en 1803; vid. M. a J. Sarabia Viejo, "El cardenal Lorenzana, editor de textos cortesianos en el siglo XVIII", Silva, 1 (2002), pp. 183-212; C. Eguía, "Un insigne editor de S. Isidoro", Miscellanea Isidoriana, Roma 1936, pp. 364-384; R. Gonzálvez, "El Cardenal Lorenzana y la edición de las obras de Santo Martino", en Santo Martino de León. Ponencias del I Congreso Internacional sobre Santo Martino de León en el VIII Centenario de su obra literaria, León 1987, pp. 563-580; R. Gonzálvez Ruiz, "Evolución histórica” (cit. n. 3), pp. 253-254. 
hoy el Alcázar (Biblioteca Pública de Castilla-La Mancha) ${ }^{31}$. Pero Lorenzana no era el único vínculo de Zelada con Toledo.

\section{Las raíces de Zelada}

El cardenal, en efecto, había nacido en Roma, en la parroquia de S. Lorenzo in Lucina, el 27 de agosto de 1717 en el seno de una familia española ${ }^{32}$ : su madre, Manuela Rodríguez, era originaria de Oviedo; su padre, Juan Jacinto, natural de Murcia, ejercía en Roma diversas funciones como intermediario entre la administración eclesiástica española y la pontificia; era expedicionero de la Dataría y, desde 1719, servía como agente al Cardenal Belluga, obispo de Cartagena residente en Roma ${ }^{33}$. En 1737, Juan Jacinto Zelada consiguió fraudulentamente para su hijo Francesco Xavier una dignidad y una canonjía dependientes del obispado de Cartagena y fue desnaturalizado y apartado de su oficio por ello ${ }^{34}$. Esta desnaturalización era conocida del diplomático aragonés José Nicolás de Azara, destinado en Roma como agente de preces desde

31. F. Esteve Barba, Catálogo de la colección de manuscritos Borbón-Lorenzana, Madrid 1942; M. Gutiérrez García-Brazales, "La Biblioteca Arzobispal de Toledo y su transformación en Biblioteca Provincial", Anales toledanos, 11 (1976), pp. 69-110; J. D. Delgado Bedmar, ”Nuevas aportaciones a la historia del fondo Borbón Lorenzana de la biblioteca de Castilla-La Mancha", Quadrivium. Patrimonio muebles restaurado en Castilla-La Mancha, Toledo 1999, pp. 43-57.

32. La fe de bautismo aparece en el ASV, Sacra Romana Rota, Processus in Admissione Auditorum, Busta IV, fasc. 134. Buenos resúmenes de la biografía de Zelada son G. Moroni, "Zelada (de) Francesco Saverio, Cardinale", Dizionario di erudizione storico-ecclesiastica da S. Pietro sino ai giorni nostri, 103 (1861), pp. 460-469; J. Card. Mejía - Chr. Grafinger - B. Jatta, I cardinali biliotecari di Santa Romana Chiesa. La Quadreria nella Biblioteca Apostolica Vaticana (Documenti e Riproduzioni 7), Città del Vaticano 2006, nr. 24: "Francesco Saverio de Zelada", pp. 239-243. Cf. F. Candel Crespo, El cardenal don Francisco Javier Zelada y Rodríguez (1717-1801), un ilustre y desconocido murciano, Murcia 2006.

33. Así lo afirma en su Ristretto della vita del C. Belluga (ASV, Fondo Albani 96, ff. 243-247v) que en su versión española empieza así: «Yo, Jacinto Zelada, expedicionero en la Dataría, natural de la Ciudad de Murcia, residencia del Obispado de Cartagena, Agente del Señor Cardenal Belluga y Moncada, con Poder general fechado el 18 de Abril de 1719, hace la siguiente relación cierta y verídica». Vid. J. B. Vilar, El Cardenal Luis Belluga, Granada 2001, reed. 2005, p. 280. Sobre la función de los expedicioneros, vid. M. Teruel Gregorio de Tejada, Vocabulario básico de la Historia de la Iglesia, Barcelona, Crítica, 1993, pp. 13-16. El Conde de Floridablanca reformó en 1778 la Agencia General de Preces en Roma con el fin de controlar los abusos que «se originan del modo arbitrario con que se acude a Roma en solicitud de las dispensaciones, indultos o gracias» encomendadas a agentes; vid. C. Fernández Espeso - J. Martínez Cardós, Primera Secretaría de Estado. Disposiciones orgánicas (1705-1936), Madrid 1972, pp. 28-29 y la cita en p. 25.

34. AEESS, Legajo 301 (comunicación del Cardenal Acquaviva a De la Quadra, 9 de enero de 1738), pp. 17-25: 24. Menciona que Juan Jacinto Zelada trabajaba para las diócesis de Valencia, Tarazona, Gerona, Tuy, Ceuta y Burgos. 
1765/6³5, y quizá está en el origen de la prevención y la inquina que sintió hacia Zelada el resto de su vida y que refleja en una correspondencia conservada por azar y muy poco ortodoxa, la que dirige a su predecesor Manuel de Roda. En ella recoge un sinfín de habladurías sobre los orígenes y las actividades de Zelada, que continuó el oficio de su padre de expedicionero ${ }^{36}$.

Entre las diócesis para las que trabajaba Zelada padre debió de incluirse la de Toledo, puesto que las Actas capitulares toledanas del 10 de febrero 1767 comunican que Francisco Javier les ha enviado una carta sobre su nombramiento de arzobispo de Petra, motivo por el cual el cabildo trató «si atendidos los muchos años que D. Jacinto Zelada, Padre de d(ic)ho Ill(ustrísi)mo Señor sirvió al Cabildo y el celo con que actualmente continúa éste en los mismos negocios y distinguido honor de que se haya revestido, convendría que el Cabildo le manifestase su aprecio con alguna expresión.» El Cabildo decide agasajarlo concediéndole la hermandad.

El nombramiento honorífico de arzobispo de Petra es un paso importante en la carrera de Ze$\operatorname{lada}^{37} \mathrm{y}$ se entiende que lo comunique a los obispados para quienes ha seguido tramitando bulas y breves. Olvidado el mal paso de 1738, el prelado no había descuidado la fuente de ingresos que podían constituir las diócesis españolas en las que su padre lo había introducido y ésa es la actividad que ha dejado huella en los archivos españoles y vaticanos desde 1752. Con el claro propósito de cultivar sus contactos españoles, Zelada no sólo escribía a la Península, también frecuentaba la embajada de Piazza Spagna, ganándose la estima del Cardenal Portocarrero ${ }^{38}$.

35. Sobre la biografía de Azara, vid. Memorias del ilustrado aragonés José Nicolás de Azara, G. Sánchez Espinosa (edición y estudio de), Zaragoza, Institución Fernando El Católico (CSIC), 2000; B. Cacciotti, "La collezione di José Nicolás de Azara: studi preliminari”, Bollettino d’Arte, 78 (1993), pp. 1-54; G. Sánchez Espinosa, La biblioteca de José Nicolás de Azara, Madrid, Calcografía Nacional - Real Academia de Bellas Artes de San Fernando, 1997.

36. Vid. El espíritu de don José Nicolas de Azara descubierto en su correspondencia epistolar con don Manuel de Roda, Madrid 1846, I, pp. 21-22: (carta de Azara del 25 de febrero de 1768): «Y a éste (Zelada) se le dan prebendas, se le dispensan pruebas, se le naturaliza en España, se le favorece siendo hijo de un cocinero, que tal fue el marido de su madre; bien que Roma asegura que su verdadero padre fue el cardenal Bolognetti». En otra misiva de 15 de febrero de 1770 (ibidem, II, pp. 22-23), Zelada ha pasado a ser «el verdadero hijo de don J. de A., dignísimo antecesor de vd. y mío». Ibidem, I, p. 151 (20 de octubre de 1768): «esta Celestina (Manuela Zelada) tiene varios emisarios que le llevan, luego que llegan, apóstatas y dispensantes; y como traigan maravedises, por pocos que sean, se los chupa como una lechuza, y después, su único hijo les saca, o no les saca, su pergamino. Había mucho más que decir sobre aquella cueva de Caco...». G. Moroni, "Zelada” (cit. n. 32), p. 463, menciona algunos pasquines que hacían escarnio de Zelada en 1774.

37. No hay espacio aquí para enumerar todos los títulos, cargos, canonjías o prebendas del Cardenal Zelada, que estudió en el Collegio Romano y en la Sapienza y se doctoró utriusque iuris el mismo año de su ordenación de sacerdote, 1740. La documentación al respecto se custodia en el ASV. Hasta el nombramiento de 1767, fue auditor de la Cámara (1754) y de la Rota (1560), canonista de la Sagrada Penitenciaría y con voto en la Signatura Apostólica “de Gratia” y Secretario de la S. Congregación del Concilio.

38. Este embajador escribe en 1752 que «el expresado Mons(eñ)or Zelada logra en esta Corte la estimación de todos por sus buenas prendas y conducta y por el desempeño en los empleos que $S(u) S($ antidad) le ha conferido y con que continúa a honrarle» (AEESS, Legajo 315, Oficios de la embajada, 16 de marzo de 1752, p. 37); cf. los términos similares del AEESS, Legajo 317, a. 1754, pp. 226-227, y Legajo 322, a. 1759, p. 86. 
En 1769 no sólo había obtenido ya numerosos beneficios eclesiásticos españoles, también recibía un sueldo por orden real, como otros prelados ${ }^{39}$. Era el modo que tenía la administración española de engrasar la maquinaria pontificia para conseguir del papa la abolición de los jesuitas, que habían sido expulsados de los territorios de la Corona en 1767.

La abolición de la Compañía de Jesús es, de hecho, la circunstancia en torno a la cual se tejió la estrecha relación de Zelada con los representantes del rey de España ante el papa, la gran oportunidad para el prelado de hacer un importante servicio a la Corona y obtener a cambio una recompensa sustancial. Este servicio consistió en convencer a Clemente XIV del interés de extinguir la Compañía y en redactar el Breve de supresión Dominus ac Redemptor (promulgado el 21 de julio de 1773$)^{40}$, labor a la que pone punto final el 6 de enero de 1773. Al hacer esto, se ha expuesto a caer en desgracia ante el papa y al odio de buena parte de la Iglesia ${ }^{41}$, pero Zelada confía en su habilidad y la jugada le saldrá bien: será capaz de servir al mismo tiempo a los intereses franceses ${ }^{42}$ y a los

39. AEESS, Legajo 218 (Reales órdenes, 20 de junio 1769), nr. 61 del ministro Grimaldi al embajador Tomás Azpuru.

40. L. von Pastor, Storia dei Papi dalle fine del Medioevo, XVI, Storia dei Papi nel periodo dell'Assolutismo dall'elezione di Benedetto XIV sino alla morte di Pio VI (1740-99), Parte II, Clemente XIV (1769-1774), Roma 1933, pp. 168-225, sobre el complejo proceso de la supresión de la Orden en Roma; pp. 192-195 y 212-215, sobre el papel del Conde de Floridablanca (José Moñino), quien redactó una minuta con 18 puntos fundamentales que fueron respetados en la formulación final del Breve. Cf. E. Pacheco, "La intervención de Floridablanca en la redacción del Breve para la supresión de los jesuítas (1772-1773)", Escuela Española de Arqueología e Historia en Roma. Cuadernos de Trabajos, III, Madrid, Junta para ampliación de estudios e investigaciones científicas, 1914 [1915], pp. 37-198; J. M. March, "Documentos insignes que pertenecieron al Cardenal Zelada tocantes a la Compañía de Jesús", Archivum Historicum Societatis Iesu, 35 (1949), pp. 118-125; R. Olaechea, Las relaciones hispano-romanas (cit. n. 27), passim.

41. Demos voz de nuevo a Azara: El espíritu de don José Nicolas de Azara (cit. n. 36), II, p. 16 (24 de febrero de 1774): «Como el papa se ha puesto en manos de Zelada y de quien sostiene a éste, toda la odiosidad de Roma cae sobre ellos, y es una desvergüenza lo que se oye.»

42. Vid. J. M. March, El restaurador de la compañía de Jesús: beato José Pignatelli y su tiempo, 2 vols., Barcelona 1935-44, I, p. 392 y n. 1 (comunicación de Moñino a Grimaldi, 7 de enero de 1773): «Zelada [...] me soltó la especie de que se vería que era buen español, cuando a su tiempo se supiese que no había querido aceptar una rica abadía en Francia. Esto quiere decir que es menester que el rey le provea en algo bueno con retención de lo que tiene.» Pero Zelada sí que recibió como recompensa las rentas de la Abadía de Marsillac; cf. El espíritu de don José Nicolas de Azara (cit. n. 36), II, p. 413 (6 de mayo de 1773): «¿Qué dirá vd. al saber que el gran cardenal Zelada se ha hecho francés, sin dejar de ser romano ni español? Acaban de conferirle una abadía de tres mil escudos de renta en aquel reino, por lo que ha trabajado en el breve de reforma de los frailes de Francia.» Moñino, sin embargo, no deja de defender a Zelada: «Ahora se dirá que éste mascó a dos carrillos, contra lo que nosotros vemos y tocamos. Han dado en que el perro ha de rabiar y que Zelada es malo; y lo que en otro tiempo se decía en Madrid, en París ahora. Es verdad que Zelada es hábil, fino, político, disimulado y capaz de hacer su negocio; pero por lo mismo sabe que no le queda en el día otro partido que tomar que el de unirse estrechamente a nosotros. De lo contrario sería sacrificado y abandonado de todos.» (AEESS, Legajo 438, Correspondencia extraoficial, f. 116, 7 de abril de 1774). 
españoles ${ }^{43}$, será nombrado Cardenal cuatro meses más tarde (el 19 de abril) y, lo que es realmente ambicioso, intentará convencer a los ex-jesuitas de que su colaboración con los enemigos de la Compañía no es una traición, sino que su función de gestor de los bienes e instituciones jesuitas va a ser beneficiosa para ellos ${ }^{44}$. En efecto, el flamante Cardenal Zelada será incluido por Clemente XIV en la Congregación destinada a ejecutar el Breve y gestionar el legado jesuita; en concreto, es nombrado Prefecto de Estudios del Collegio y Seminario romanos y preside del Gesù ${ }^{45}$.

43. Vid. J. M. March, El restaurador (cit. n. 42), I, pp. 347-351: despacho del embajador José Moñino (Conde de Floridablanca) al ministro Grimaldi, del 29 de abril de 1773: «Zelada me explicó sus empeños, pero son crecidos. Díjome que debía 15 mil escudos. El se hizo cargo que no era justo pretender que se le pagasen todos; y yo le insinué que era mejor obtener algún regalo de presente, y alguna provista de alguna prebenda o beneficio. Considerando que este hombre ha servido bien, y que todavía nos puede servir, no sólo en el negocio de extinción, sino en otros, porque el Papa me ha explicado que quiere continuar tratando con él, y a este fin seguirá recibiéndole los lunes por la noche, aunque ha cesado en su Secretaría del Concilio, me parece que se le entregue una cédula de seis o siete mil escudos, y que se le provea en alguna prebenda o beneficio; puesto que no es necesario que sea pensión ni cosa simple.» (ibidem, p. 348). La confirmación de las canonjías de Sevilla y Córdoba para Zelada sale de Madrid el 20 de julio de 1773 (AEESS, Legajo 222, Reales órdenes).

44. El espíritu de don José Nicolas de Azara (cit. n. 36), II, p. 380 (28 de enero de 1773) : «yo tengo tan mala opinión del sugeto (Zelada), que no me puedo persuadir que deje de echarlo a perder todo, ni que deje de comunicar cuanto sabe al P. Ricci su superior (de los jesuitas), ni dejar de entendérsela con el Papa, haciendo dos y más papeles, si es menester en la comedia, para collonarnos.»; cf. ibidem, p. 582: «yo tengo por seguro que se la entenderá con los jesuitas y más aún con el Papa, tan fecundo como él en mentiras y trapazas.» Cf. el testimonio del jesuita Manuel Luengo cuando Zelada muere, I. Fernández Arrillaga (ed.), El legado del P. Manuel Luengo, S.I. (1767-1815). Diario de la expulsión de los jesuitas de España, colección de papeles curiosos y varios (índices), Alicante, Instituto Alicantino de Cultura "Juan Gil-Albert", 2003, volumen correspondiente a 1801, pp. 269-272: «Muerte del Cardenal Francisco Xavier Zelada, nacido en Roma de padre español, discípulo favorecido y afecto de los Jesuitas hasta su destierro de España. Desde aquel tiempo enemigo declarado de ellos y entra en todo lo que se hace contra la Compañía con tanto favor que logra pensiones de varios cortes y todo el favor del Ministerio de Madrid. Por el mismo mérito logró muchas rentas y empleos en Roma. Se alaban mucho sus limosnas a pobres y obras pías y yo no sé si bastarán para librarle de la obligación de retrasar ofensas y calumnias contra la Compañía.»

45. ASR, Patrimonio ex gesuitico, Reg. 6 (6 de septiembre de 1773). Vid. J. M. March, El restaurador (cit. n. 42), I, p. 301; Id., "Documentos insignes" (cit. n. 40), p. 118; R. García Villoslada, Storia del Collegio Romano dal suo inizio (1551) alla soppressione della Compagnia di Gesù (1773), Roma 1954, p. 315; M. A. Quesada, "Il Collegio Romano negli anni della soppressione della Compagnia di Gesù (1773-1824)", en Il Collegio Romano dalle origini al Ministero per i Beni e le Attività Culturali, C. Cerchiai (a c. di), Roma, Istituto Poligrafico e Zecca dello Stato, 2003, pp. 125-148: 125. 
La responsabilidad de Zelada en el Collegio Romano fue, sin duda, determinante en la formación de sus colecciones de instrumentos científicos ${ }^{46}$ y antigüedades ${ }^{47}$. Las circunstancias de la supresión, que propiciaron la falta de control, el desorden y la dispersión del patrimonio jesuita, oscurecen la comprensión del proceso que llevó a la disgregación de sus colecciones de arte y sus bibliotecas, pero parece evidente que éstas se incorporaron progresivamente a las vaticanas o a las cardenalicias (sin olvidar que la frontera entre las primeras y las segundas no era nítida o sólo lo era mientras los cardenales vivían) y que este proceso nunca tuvo vuelta atrás, a pesar de compensaciones económicas o intercambios en el momento de la confiscación o posteriormente. Por lo que sabemos, Zelada empobreció el Museo Kircheriano (que se había creado en 1651 a partir de la donación de Atanasius Kircher) enviando muchas piezas (inscripciones, medallas, monedas, vasos etruscos, pinturas) al Vaticano y al Museo Capitolino.

En 1797, tras dejar su cargo de Secretario de Estado (1789-1796) ${ }^{48}$, y con 80 años cumplidos, quiso organizar sus posesiones consignando al Vaticano algunos objetos jesuitas a cambio de los cuales entregó al Collegio Romano sus medallones, monedas, pesos, etc. ${ }^{49} \mathrm{El}$ testamento del 1 de octubre de 1800 confirma la decisión de donar al Collegio estas colecciones localizadas en él o en la residencia de Zelada, una donación que sería en parte una devolución:

«Avendo io accommodato alcune Camere nel Collegio Romano, ove qualche volta sono andato ad abitarci per assistere con più comodo alla Prefettura di quelli Studi, Bibliotheca, Museo, e Specola, dichiaro in primo luogo, che quanto al tempo della mia morte si troverà in dette Ca-

46. Una de las iniciativas más conocidas de Zelada en el Collegio fue la construcción en 1787 de la Specola u Observatorio astronómico que causó gran sensación entre los contemporáneos y aún preside el tejado del Collegio. Colaboró con él el profesor de matemáticas de esta institución, Giuseppe Calandrelli, quien sería su director y escribió una Lettera sopra l'eclisse solare accaduta li XVII. ottobre MDCCLXXXI. diretta all'E.mo Signor Cardinale Francesco Saverio De Zelada, Roma 1781; se conserva un ejemplar en la biblioteca Guido Horn d'Arturo, en la Università degli Studi di Bologna, Misc. Leg. XXI.11.

47. Vid. J. M. March, "Documentos insignes" (cit. n. 40), p. 119; M. A. Fugazzola Delpino - E. Mangani, "Il Museo Kircheriano", en Il Collegio Romano (cit. n. 45), pp. 265-319: 272; A. M. De Strobel - M. Serlupi Crescenzi, "Clemente XIV e Pio VI fondatori di nuovi musei. La dispersione delle collezioni gesuitiche e la loro assimilazione nelle raccolte vaticane", en Athanasius Kircher. Il Museo del Mondo, E. Lo Sardo (a c. di), Roma 2001, pp. 287-291: 289. Zelada fue autor de un De nummis aliquot aeris uncialibus epistola, Roma 1778, donde trata de los cambios de valor durante y después de las guerras púnicas e incluye un catálogo de su colección de monedas, que legó al Collegio Romano (vid. infra). Es el único libro que publicó el Cardenal.

48. Éste es sin duda el cargo de mayor responsabilidad que desempeñó Zelada y excusó su renuncia por problemas de salud, aunque la razón real fue probablemente la inminente invasión francesa; vid. M. E. Micheli, "Naturalia e artificialia" (cit. n. 29), p. 232.

49. Città del Vaticano, Biblioteca Apostolica Vaticana, Arch. Bibl., vol. 97, ff. 165-186, documento de A. Battaglini, Prefecto de los museos privados y de la biblioteca de Zelada, en el que da fe de haber entregado en 1797 a Monseñor Giuseppe Reggi, Custodio de la Vaticana, "impressiones" de los sigilli procedentes del Museo Kircheriano y después en poder de Zelada, «con molti suoi proprii, ed altri, che pur riteneva della Vaticana, compensando soprabbondevolmente il Museo del Collegio romano con il dono della copiosa raccolta di medaglie, monete antiche e moderne in oro, argento, pesi, idoli e la ricca collezione di storia naturale.» 
mere di mia pertinenza, tutto vi debba rimanere niuna cosa eccettuata a disposizione de' S(igno) ri Cardinali Protettori del Collegio Romano; voglio inoltre che dal mio Esecutore Testamentario si faccia trasportare al Coll(egi)o Romano tutto il mio Museo, tanto Antiquario, quanto di Storia Naturale, niuna cosa eccettuata, acciò di tutto collocato nelli respettivi bracci del Museo del Coll(egi)o Romano detto Kirkeriano, al quale intendo di lasciarlo a titolo di Legato, ed in ogni altro miglior modo. Parimente intendo di donare alla Specola del Coll(egi)o Romano tutti quegli Instrumenti Astronomici, Mattematici e Fisici, che da casa mia sono stati già trasportati alla detta Specola, ma voglio inoltre, che se al tempo della mia morte si trovassero presso di me altri consimili istrumenti Astronomici, Mattematici e Fisici, siano parimente trasportati alla sud(ett) a Specola del Coll(egi)o Romano, per essere incorporati agli altri esistenti, essendo questa la mia volontà.»

Confirmando las sospechas despertadas en todos los que hemos examinado la labor de Zelada en la gestión de la Orden jesuita, Juan Andrés señala que «es un portento ver tantas y tan varias preciosidades unidas por un hombre solo en el breve transcurso de pocos años», haciendo referencia al período transcurrido entre 1773 y $1785^{50}$. Aunque no tenemos prueba de ello, es verosímil que las rarezas orientales que hoy se custodian en Toledo procedan de las colecciones jesuíticas, pues la Compañía tenía cierta presencia en China, compitiendo con la Congregación de Propaganda Fidei ${ }^{51}$.

Uno de los grandes beneficios personales que Zelada obtuvo de estar al frente del Collegio Romano fue disponer como bibliotecario de un estudioso de gran valía, el jesuita Pietro Lazzerì. En el Collegio, Lazzerì había catalogado la biblioteca impresa ${ }^{52}$ y, tras la extinción de la Compañía, siguió allí como bibliotecario y profesor de historia eclesiástica ${ }^{53}$, compaginando estas actividades con el cuidado de la biblioteca de Zelada. En realidad, no parece haberse prodigado mucho en la sección griega de la biblioteca: el Toledo, ABC 88-22, que contiene los índices de 23 manuscritos de Zelada, sin duda pensados para ser incorporados en los respectivos volúmenes, pero finalmente reunidos y encuadernados juntos, conserva sólo 3 breves menciones de Lazzerì

50. Cartas familiares del abate D. Juan Andres (cit. n. 9), I, p. 188. En estos años, Zelada fue nombrado el 21 de mayo de 1773 Protector de la Orden de los Betlehemitas, en las Indias Occidentales (ASV, Sec. Brev., 3767 , f. 1), en 1780 de los Trinitarios (ASV, Sec. Brev. 3943, f. 5) y en 1783 Camerario del S. Collegio.

51. G. Haenel, Catalogi librorum manuscriptorum qui in bibliothecis Galliae, Helvetiae, Belgii, Britanniae M., Hispaniae, Lusitaniae asservantur, Lipsiae 1830, cols. 997-998; R. S. Parro, Toledo en la mano o descripción histórico-artística de la magnífica Catedral..., 2 vols., Toledo 1857 (reimpr. Toledo 1978), I, p. 686, sobre «varios manuscritos en el antiguo papiro, en pizarra, en plomo en tablillas chinas y en hojas de palma». Zelada poseía además documentación jesuita y papal sobre las misiones en China (Toledo, ABC 26-13 al 19) y en Oriente Próximo (Toledo, ABC 26-20). J. M. March, "Documentos insignes" (cit. n. 40), p. 120 ha localizado documentación jesuita en los Toledo, ABC 87-13 y 87-17.

52. R. Mercati, Note (cit. n. 18), p. 73, n. 1, p. 82, n. 4; R. García Villoslada, Storia del Collegio Romano (cit. n. 45), pp. 188-193; J. Diamond, "A Catalogue of the old Roman College Library and a Reference to Another", Gregorianum, 32 (1951), pp. 103-114. Lazzerì realizaría la catalogación entre 1754 y 1773.

53. R. García Villoslada, Storia del Collegio Romano (cit. n. 45), p. 315. 
a los actuales Toledo, ABC 49-21, 31-29 (= Matrit. Vitr/26-4) y a un códice persa, pero también un estudio detallado de las actas conciliares que contiene el Toledo, ABC 8-22. Éste es el único índice compuesto por él que conserva el Toledo, ABC 88-22 (PI. 5).

Que no fuera Lazzerì el autor de las demás descripciones sugiere que el nombramiento de Zelada como Cardenal Bibliotecario el 15 diciembre de $1779^{54}$ dio un nuevo giro a la historia de su colección manuscrita. En efecto, las restantes descripciones incluidas en el Toledo, ABC 88-22 y en sus respectivos códices ${ }^{55}$ son obra del scriptor graecus de la Vaticana (1758-1780), el quiota Raffaele Vernazza (PI. 6). Si hizo este trabajo de descripción de los códices griegos de Zelada cuando éste ya era Cardenal bibliotecario, entonces dedicó a tal tarea sus últimos meses de vida, de enero a octubre de $1780^{56}$.

Desde su nombramiento como Cardenal Bibliotecario, Zelada ocupó un apartamento de una quincena de ambientes en la Torre dei Venti o Belvedere ${ }^{57}$, pero no es allí donde sus libros se mezclarían con los vaticanos, dando pie a la acusación de que con los códices enviados a Toledo iban algunos de la Vaticana ${ }^{58}$. Mercati, con buena fe, atribuye a la "dimenticanza" de su antecesor Zelada la no devolución de algunos manuscritos que verosímilmente se había llevado

54. ASV, Secr. Brev. 4361, ff. 52-58v.

55. Así los Toledo, ABC 9-14 y 99-16, pero sin duda hay más ejemplos. En este último, que contiene una copia de mediados del siglo XVI de León el Sabio, Taktika, una nota al final del pinax recoge la muerte de Vernazza en 1780: Scripsit manu sua D. Raphael Vernassa Chius in Vaticana Bibliotheca scriptor graecus mortuus mense octobr. a. 1780 .

56. R. Mercati, Note (cit. n. 18), p. 72, n. 2; J. Bignami Odier, La Bibliothèque Vaticane de Sixte IV à Pie XI. Recherches sur l'histoire des collections de manuscrits, (Studi e Testi 272), Città del Vaticano 1973, pp. 129-130, n. 111; S. Lilla, I manoscritti Vaticani Greci (cit. n. 16), p. 97. Vernazza redactó un inventario de los códices Colonna y los Ottoboniani; también organizó la colección de papeles de Allacci y corrigió el Oficio griego para los basilianos. Los códices hebreos de Zelada fueron asimismo descritos por el scriptor de la Vaticana Johannes Antonius Constantius y sus índices colocados al comienzo de los respectivos manuscritos; vid. J. M. Millás Vallicrosa, "Manuscritos hebraicos" (cit. n. 15), p. 396.

57. J. J. de Lalande en su Voyage en Italie (Voyage d'un françois en Italie, fait dans les années 1765 et 1766 : contenant l'histoire \& les anecdotes les plus singulières de l'Italie, \& sa description, les moeurs, les usages, 9 vols., Paris 1786, IV, p. 2, localiza los apartamentos de Zelada en la parte superior de la Torre de' Venti o Belvedere: «Le cardinal Zélada qui les habite actuellement en qualité de bibliothécaire du Vatican, les a fait orner de peintures \& de meubles précieux.» y cf. ibidem, p. 35, sobre la escalera que Zelada ordenó construir para unir la entrada del Museo con la galería geográfica o de planos. Cf. el Diario di Pio VI correspondiente al 19 de agosto de 1780: «Dall’ em. de Zelada si fa ariattare e nobilmente dipingere il passetto che resta sopra il grand' ovalo del giardino della Pigna al Vaticano che conduce nel suo appartamento, determinato di trasportare in esso il più pregevole del suo Museo.» (cit. por L. von Pastor, Storia dei Papi [cit. n. 40], XVI, 3, p. 46, n. 7); G. Moroni, "Zelada" (cit. n. 32), p. 464. Las salas se decoraron con las principales realizaciones arquitectónicas de Pío VI en Roma. En los actuales Museos Vaticanos se visita la Sala del Meridiano, que formaba parte de las estancias de Zelada y que contenía numerosos instrumentos astronómicos, entre los cuales, un meridiano.

58. Gaetano Marini, prefecto de los Archivos y de la Biblioteca Vaticana, escribía el 5 de mayo de 1802 a propósito de la donación de Monseñor Acquaviva: «Ed è poi cosa degna di ammirazion grande che un Prelato Napoletano, il quale non ebbe mai alcuna relazione colla detta Biblioteca (Vaticana), abbia pensado ad essa moren- 
prestados $^{59}$, pero la verdad es que de ninguno de los manuscritos griegos de Toledo se puede afirmar que fueron tomados por él de la Vaticana, una realidad que concuerda con el testimonio de su bibliotecario Battaglini, que sí menciona algunos volúmenes en latín pertenecientes a la colección papal ${ }^{60}$. El famoso Platón Città del Vaticano, Biblioteca Apostolica Vaticana, gr. 1, nunca estuvo en poder de Zelada: el número de orden $\left(n .^{\circ} 796\right)$ en un recuadro de papel antiguo pegado sobre la guarda del códice vaticano ${ }^{61}$ no tiene nada que ver con los pequeños números de orden de los códices de Zelada.

Entre éstos, sí hay códices papales, pero no desaparecieron de la Vaticana en el siglo XVIII, sino que fueron extraviados mucho antes, probablemente durante el Sacco de Roma (1527). Es el caso del Toledo, ABC 101-16, cuya copia del De regno de Dión de Prusa sirvió para la traducción al latín realizada en la Vaticana por Gregorio Tifernate ${ }^{62}$. Otro códice famoso que estuvo en poder de un papa Medici es el Plutarco Toledo, ABC 51-5 (PI. 7) ${ }^{63}$. Estos y otros códices zeladianos habían pertenecido a la colección Sforza, que después fue adquirida por el Cardenal Passionei entre 1698 y 1708 y pasó a la Angelica en 1762, aunque algunos códices acabaron en la biblioteca de los Chigi y en la de Zelada ${ }^{64}$. Junto a esta procedencia de la colección Sforza, cabe mencionar también la de la biblioteca del capellán anglicano Thomas Wagstaffe († 1770),

do, quando il poc'anzi defunto Card. Bibliotecario (Zelada) 1'ha preterita del tutto, privata anzi di alcuni manoscritti ch'erano suoi.» BAV, Arch. Bibl., vol. 102, f. 28, cit. por G. Mercati, Note (cit. n. 18), p. 81.

59. G. Mercati, Note (cit. n. 18), p. 84; S. Lilla, I manoscritti Vaticani Greci (cit. n. 16), pp. 90-92.

60. Bonon. 4256, II, pp. 681-682: «Imperocchè come a Cardinale Bibliotecario ossia Protettore della detta Biblioteca fu adesso consegnato per trarne copia; e sappiamo, che in tempo della democratica così detta Repubblica Romana, cioè nel 1798, assente il cardinal de Zelada, e chi aveva la custodia della di lui libreria, molti volumi non suoi furono incassati, e mandati a Toledo. Fra questi deggiono contarsi XI. tomi in fog(lio) piccolo col titolo $=$ Memoria di famiglie, ed altri VI. tomi pure in fog(lio) piccolo con titolo =Memorie di S. Giovanni in Laterano= e forse altri volumi di opere di Monsig. Pier Luigi Galletti Vescovo di Cirene, il quale fecce dono di tutti i propri manoscritti alla Biblioteca Vaticana, di cui è stato scrittore in lingua latina. Reclamant ad dominum. Non s'intenda però questo se trattisi di codici Hebraici, Greci, Arabi, Cinesi, ed altre lingue Orientali, de' quali gran copia possedevansi dal suddetto Sig. Cardinale, e che pure furono trasmessi a Toledo. Intendesi qui solo parlare di quelli, che sono nelle lingue, le quali si leggono nel presente catalogo.»

61. G. Mercati, Note (cit. n. 18), Tav. 6.

62. M. Menchelli, "Il discorso Sulla regalità I di Dione di Prusa nelle traduzioni di Gregorio Tifernate e Andrea Brenta", en Tradurre dal greco in età umanistica. Metodi e strumenti, M. Cortesi (ed.), Firenze 2007, pp. 17-34; Ead., “Toledo, ABC Tolet. 101/16”, en Lecturas de Bizancio (cit. n. 24), nr. 43, pp. 192-193.

63. Vid. Ch. Graux - A. Martin, "Rapport" (cit. n. 1), pp. 264-266; G. Mercati, Note (cit. n. 18), p. 78; G. B. A. Fletcher, "The Toledo Ms. of Plutarch's Moralia", Classical Quarterly, 21 (1927), pp. 166-176; J. Métayer, "Un manuscrit grec disparu du Vatican et retrouvé à Tolède", Revue de Philologie, de littérature et d'histoire anciennes, 45 (1971), pp. 274-280: 279.

64. Sobre los códices Sforza, vid. G. Mercati, Note (cit. n. 18), pp. 67-77; sobre los del Cardenal Passionei, vid. A. Serrai, Domenico Passionei e la sua biblioteca, Milano, Sylvestre Bonnard, 2004. Para J. Métayer, "Un manuscrit grec disparu" (cit. n. 63), pp. 278-279, los manuscritos que no están en la Angelica pasarían en 1687 al cardenal Gualterio Slusio y después al cardenal Imperiali; Zelada los adquiriría en 1796. 
especializada en el estudio de textos litúrgicos, que desde 1738 pudo consultar en la Biblioteca Vaticana y en la Barberini ${ }^{65}$.

Por lo que respecta a los impresos de Zelada, el Cardenal Roverella consiguió que el papa Pío VII los adquiriera y depositara en el Quirinale, donde se mezclaron con los del propio Pío VII. Allí, las malas condiciones de conservación permitieron la sustracción de algunos volúmenes y el deterioro de otros, como comprendió Battaglini al intentar organizar los libros y separarlos de los del papa. Pero el intendente francés, Daru, ordenó su envío inmediato al Vaticano, con la excepción de 3.000 destinados a una Biblioteca del sovrano Popolare o Secolare ${ }^{66}$. La biblioteca de Zelada fue así incorporada a la Vaticana y catalogada por Battaglini y Baldi, con excepción de algunos duplicados que volvieron al Quirinale y se unieron a la biblioteca de Pío VII, que ahora se encuentra en Cesena.

Ni los impresos ni los manuscritos son mencionados por Zelada en su testamento del 5 de septiembre de 1800, con la excepción de los 5 volúmenes del Pontifical regalados por Clemente XIII cuando lo consagró Arzobispo de Petra, más un sexto pontifical de pequeño tamaño, que dona a la Catedral de Santiago de Compostela, de la que es archidiácono. Del mismo modo en que enumera los distintos regalos que destina a esta y otras diócesis españolas, Zelada podría haber mencionado la donación realizada poco antes a Toledo. La única explicación de no haberlo hecho es que no quiso remover una cuestión tan comprometida, producto de una decisión de la que quizá ya por entonces se arrepentía.

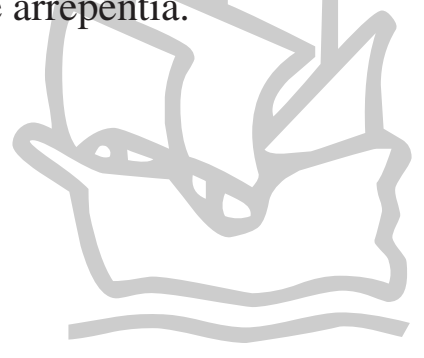

65. El Toledo, ABC 31-32 es, de hecho, el índice que Wagstaffe confeccionó del famoso Eucologio Barberino. El Toledo, ABC 31-31 es un leccionario datable en el Sur de Italia a mediados del siglo XII y completado por Wagstaffe (PI. 8). El Matrit. 4694 quizá le perteneció también. Vid. G. Mercati, Note (cit. n. 18), p. 73.

66. Así lo cuenta Battaglini en el Breve e sincero Ragguaglio dell'Operato del Canonico Angelo Battaglini Custode della Biblioteca Vaticana nell'assenza da Roma di N.S. papa Pio Settimo. Vid. G. Mercati, Note (cit. n. 18), pp. 81, 83, 175; J. Bignami Odier, La Bibliothèque Vaticane (cit. n. 56), pp. 209 y 220; D. Gnola, "La biblioteca di Pio VII", Il libro in Romagna. Produzione, commercio e consumo dalla fine del secolo XV all'età contemporanea. Convegno di studi (Cesena, 23-25 marzo 1995), L. Baldacchini - A. Manfron (a c. di), Firenze, Olschki, 1998, II, pp. 697-712. Como han estudiado P. J. van Kessel - D. Bodart, "La collection d'opuscules relatifs aux dernières années du Régime autrichien et à la Révolution brabançonne, rassemblée par le nonce Antonio Felice Zondadari”, Bulletin de l'Institut historique belge de Rome, 41 (1970), pp. 593-752: 596-597, entre los impresos de Zelada había una colección especial de folletos revolucionarios enviados por el nuncio en París, el abad de Salamont. Vid. C. Ledré, L'abbée de Salamont correspondant du Saint-Siège pendant la Révolution, Bibliothèque d'Histoire ecclésiastique de France, Paris 1965; E. De Richemont, Correspondance secrète de l'abbé de Salamon, chargé des affaires du Saint-Siège pendant la Révolution, avec le cardinal de Zelada, 1791-1792, Paris 1898. 


\section{INMACULADA PÉREZ MARTÍN}

Los manuscritos griegos del Cardenal Zelada: una biblioteca romana en la Catedral de Toledo

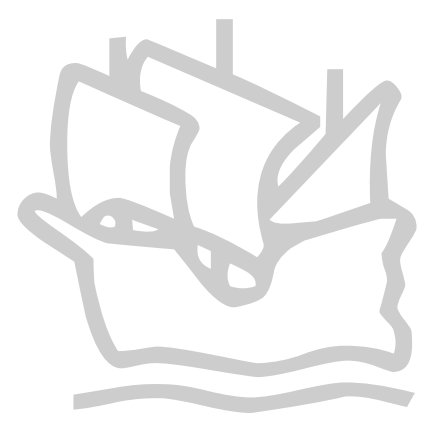




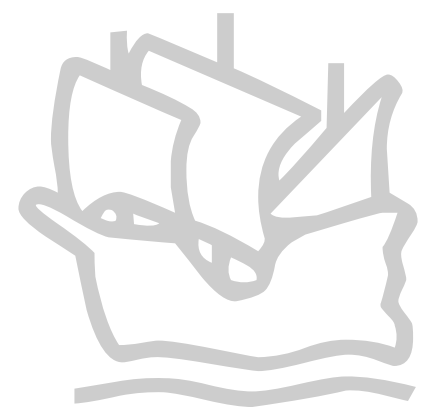

O BREPOLS PUBLISHERS 


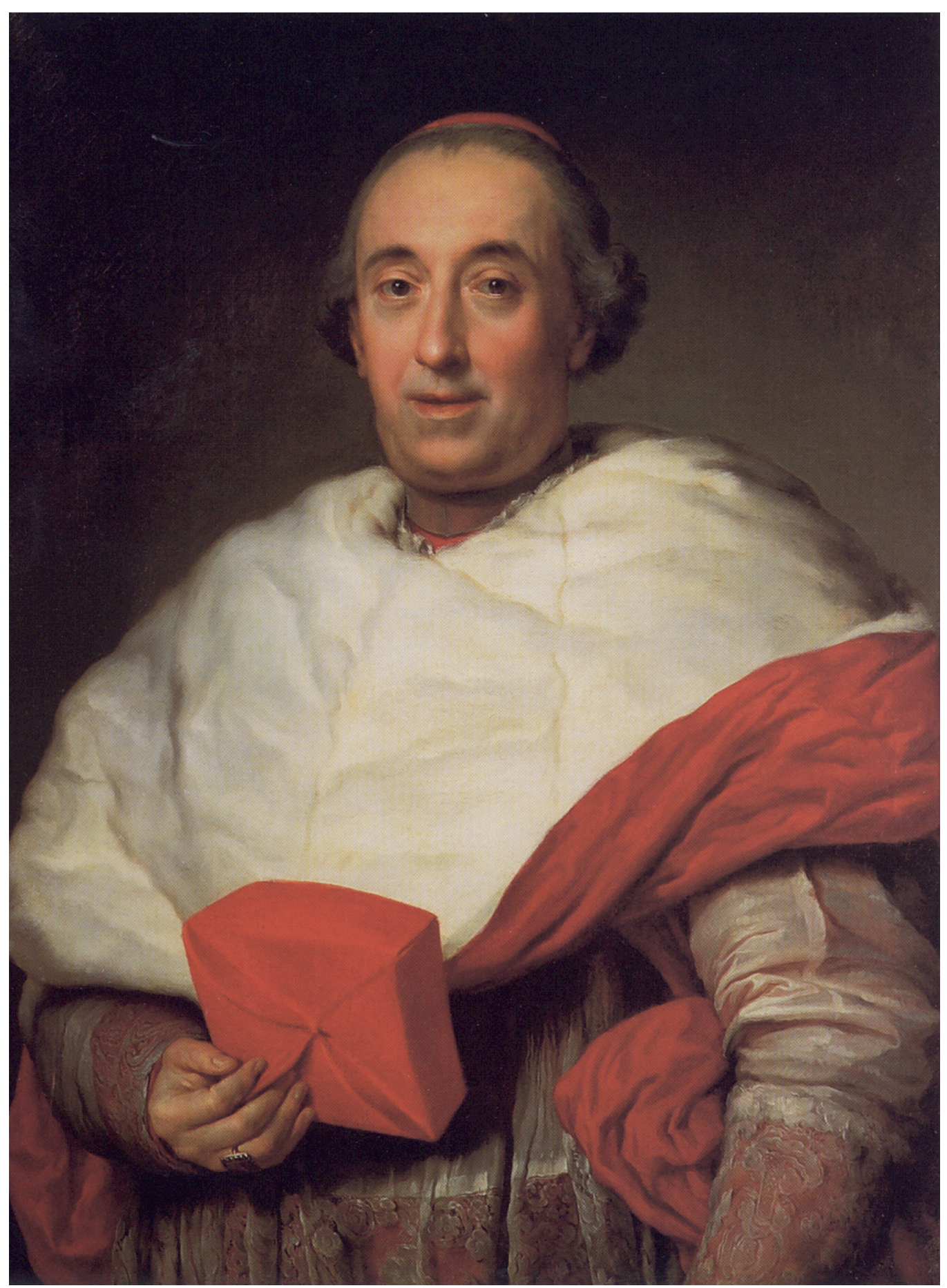

Pl. 1: Chicago, The Art Institute, Retrato del Cardenal Zelada, por Rafael Mengs 


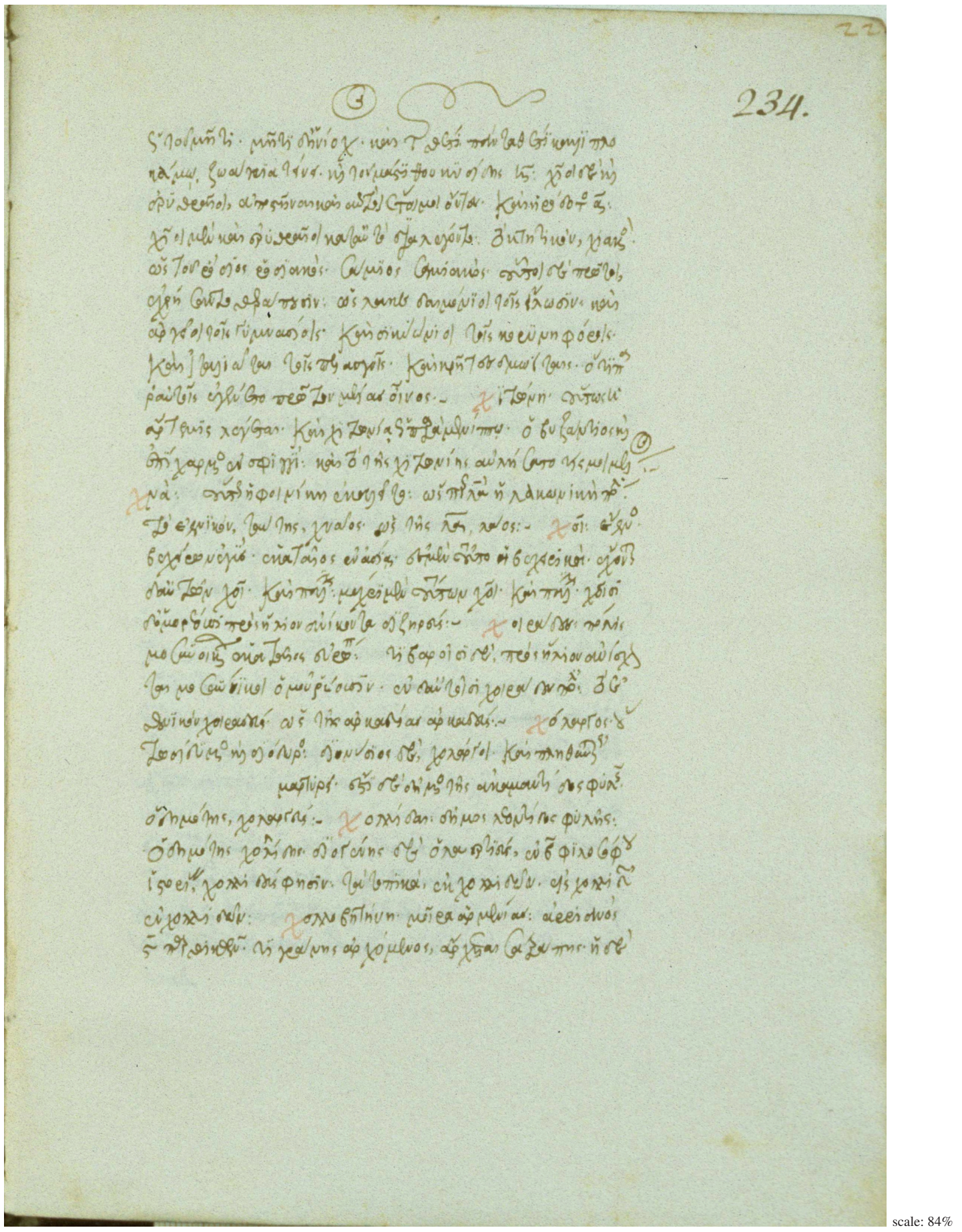

Pl. 2: Toledo, ABC 45-30, f. 234: Esteban de Bizancio, De civitatibus; copiado en Florencia en 1496 por Miguel Suliardo 


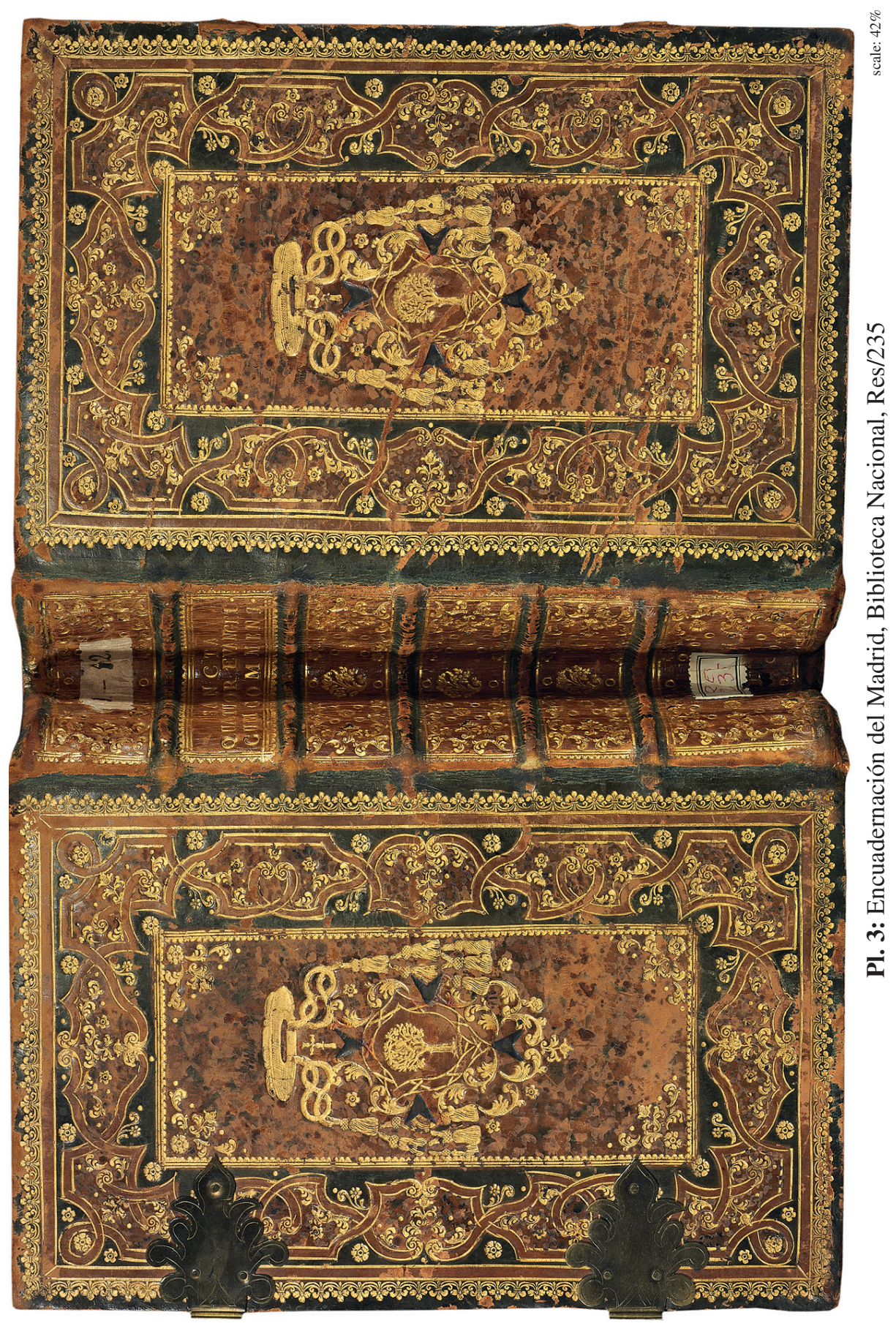




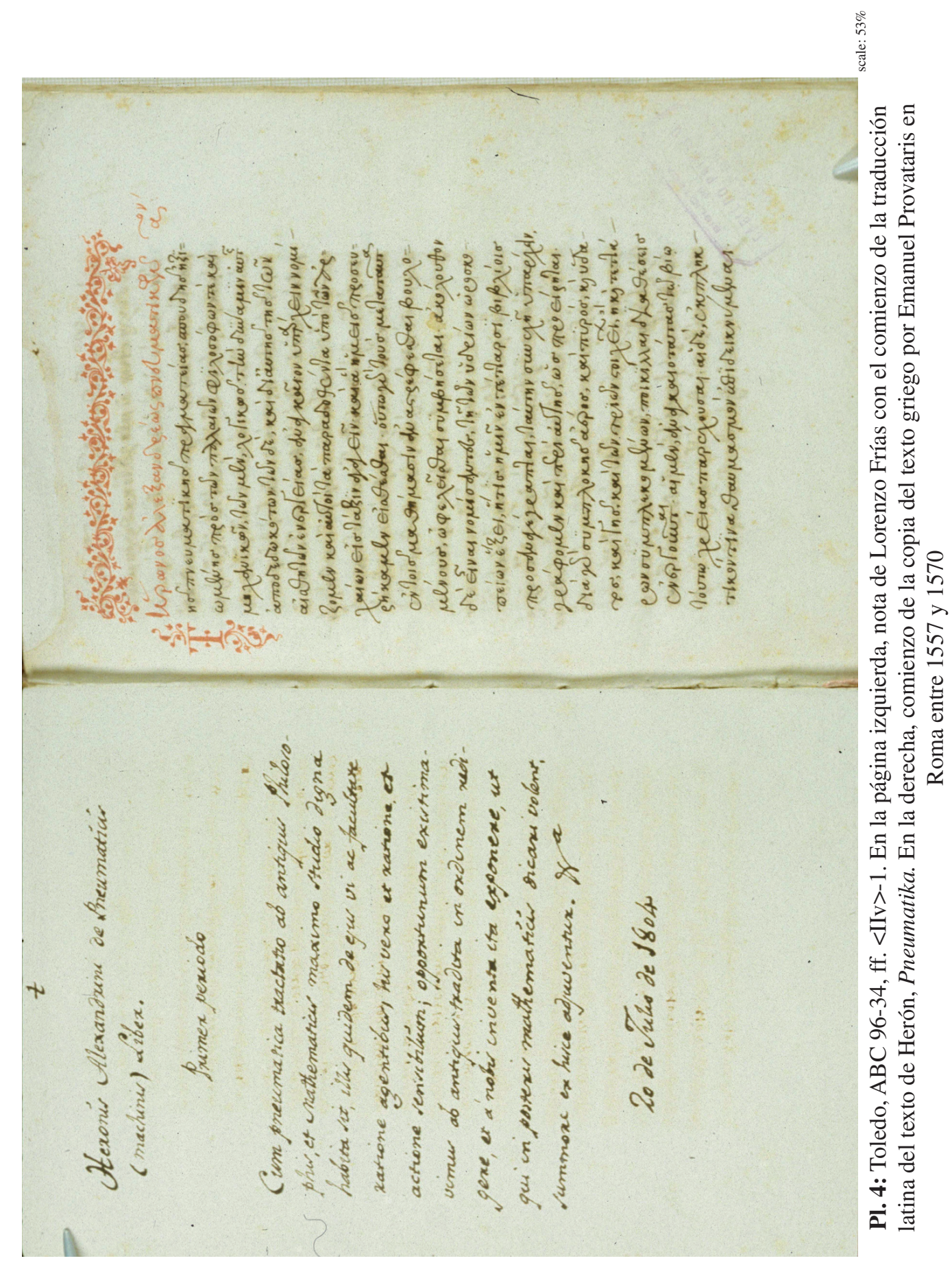




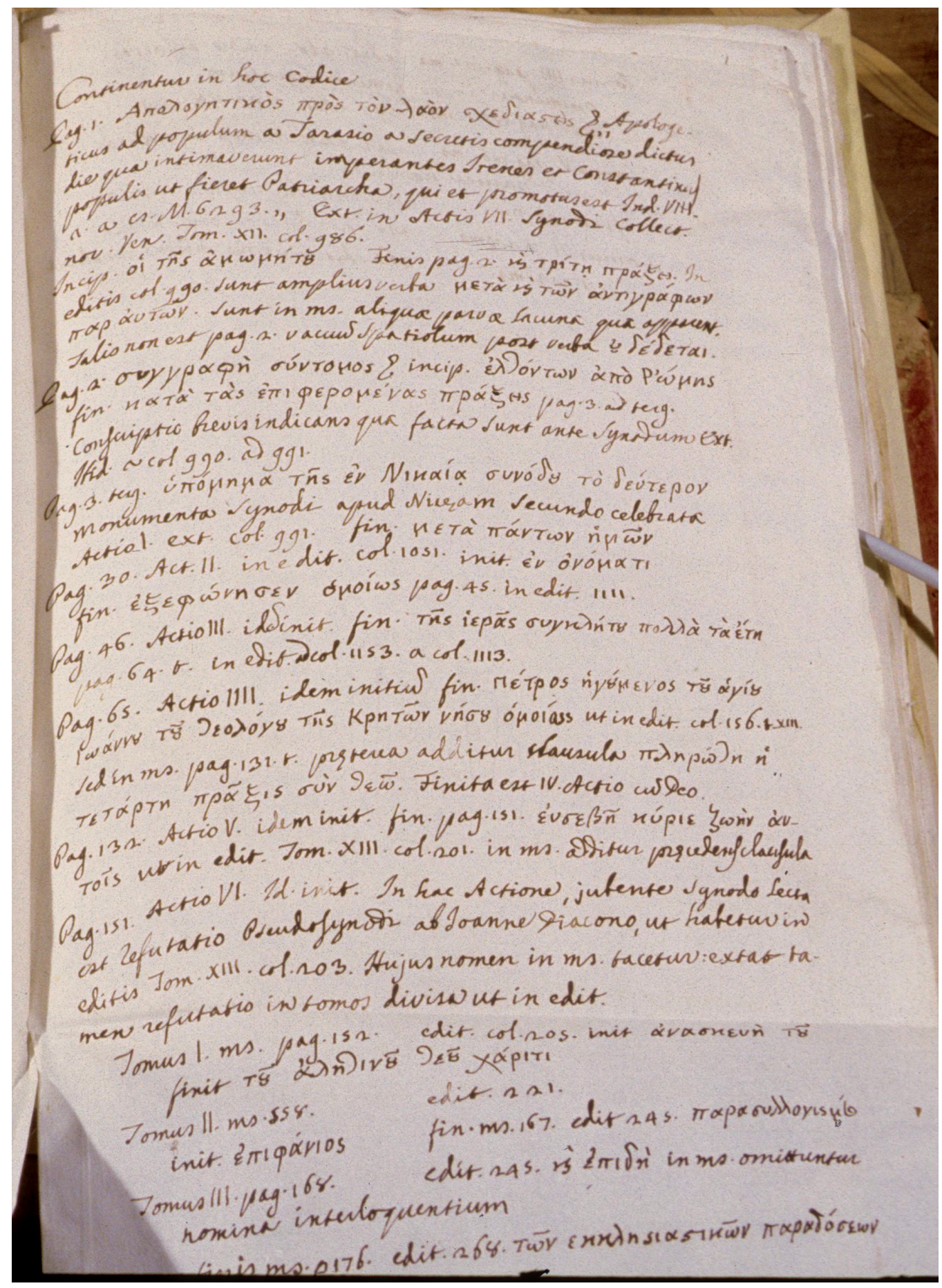

Pl. 5: Toledo, ABC 88-22, f. I: pinax del Toledo, ABC 8-22, compuesto por Pietro Lazzerì, bibliotecario del Cardenal Zelada 


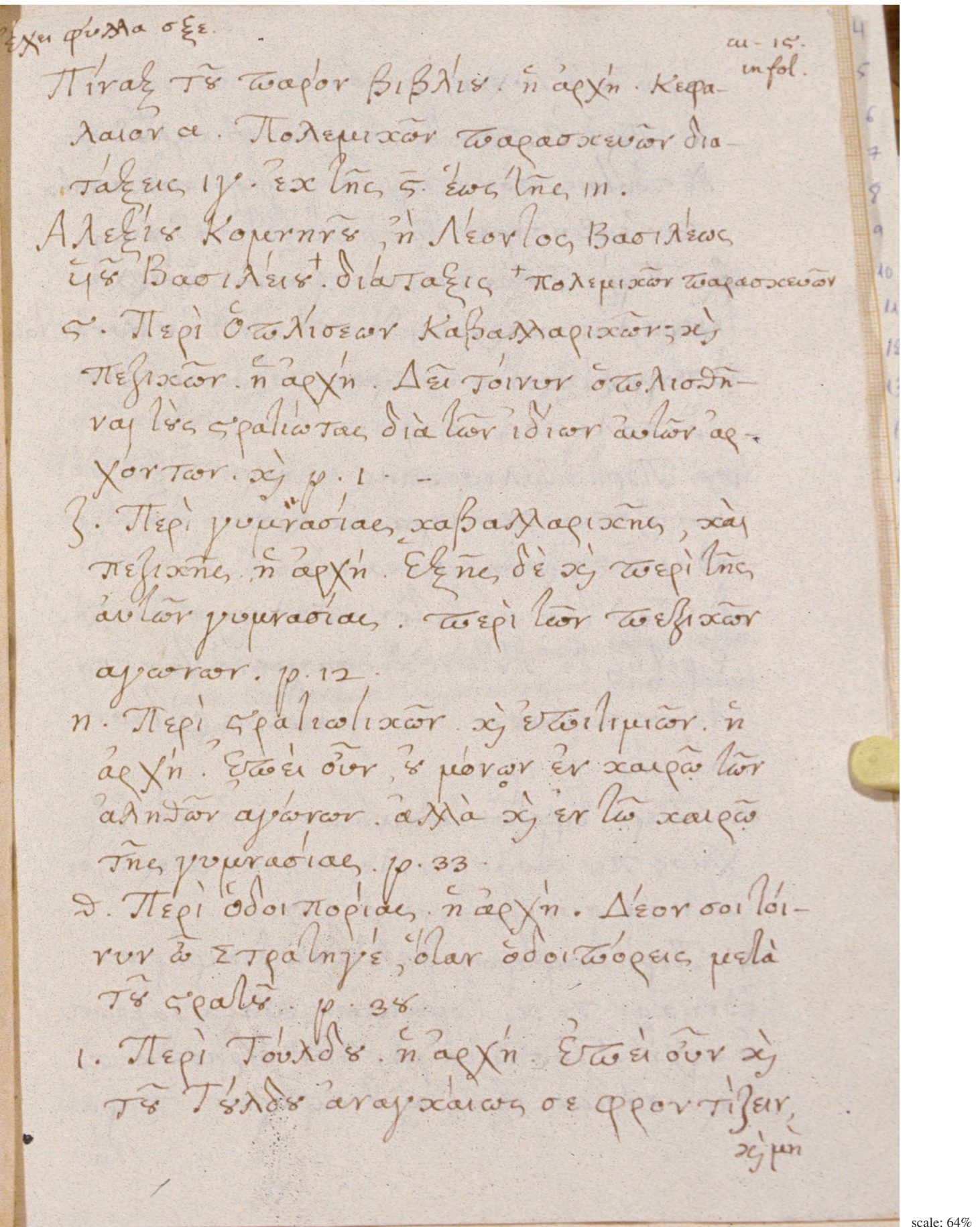

PI. 6: Toledo, ABC 99-16: pinax del scriptor de la Biblioteca Vaticana Raffaele Vernazza 


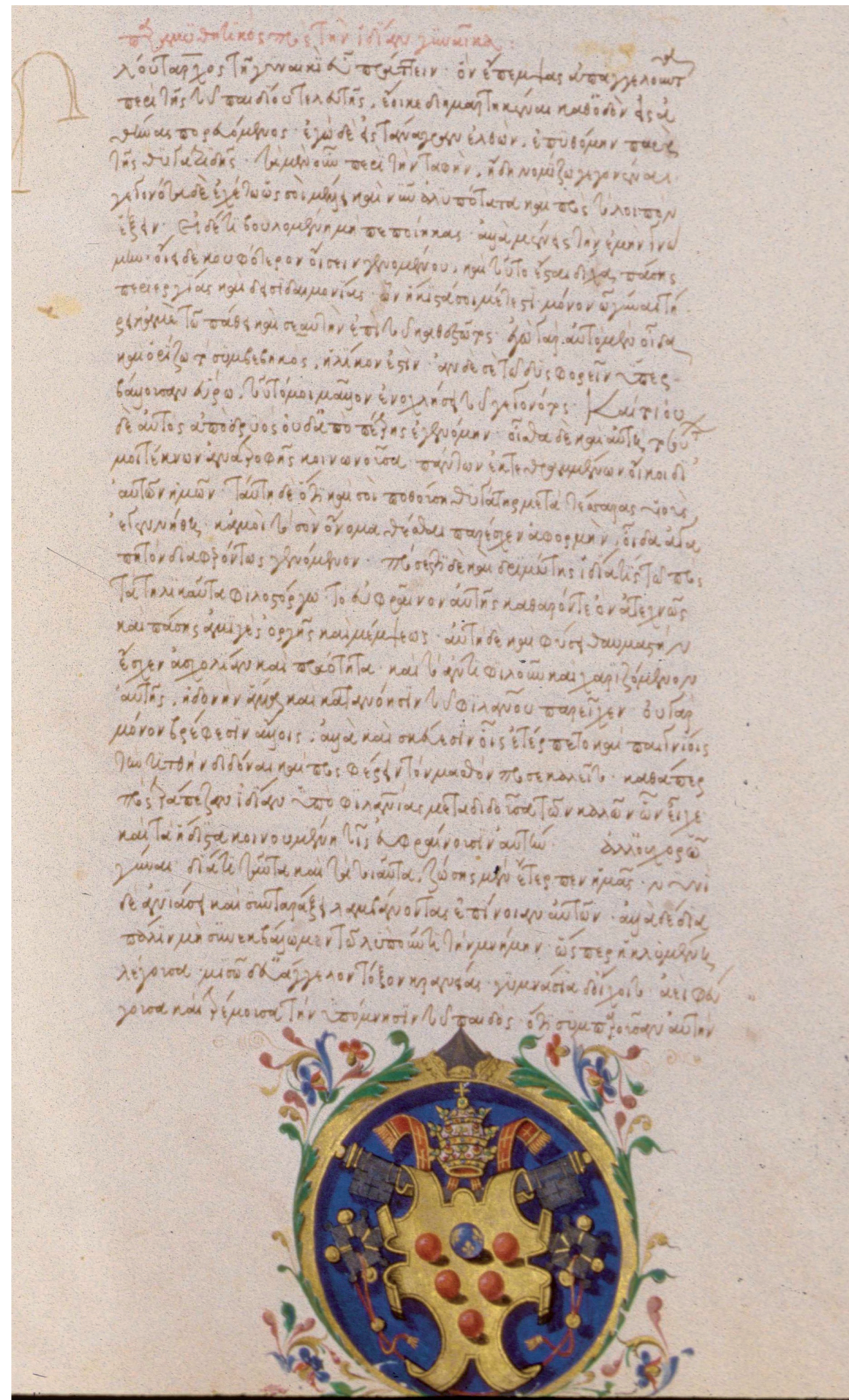

Pl. 7: Toledo, ABC 51-5, p. 3: Plutarco, Moralia. Sello de un papa Medici 


\section{$\sigma a \beta \beta a r s o r ~ \hat{s}$}

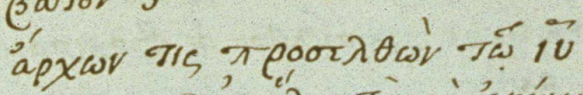

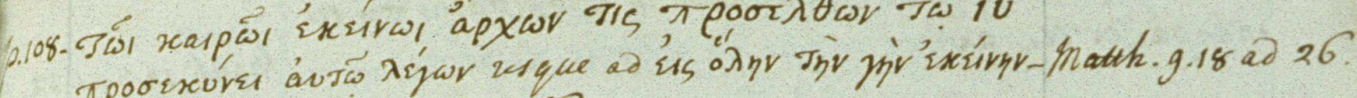

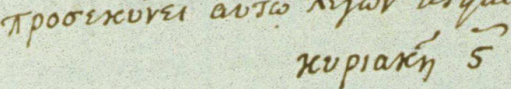

$$
\text { xupiaxín } \overrightarrow{5}
$$

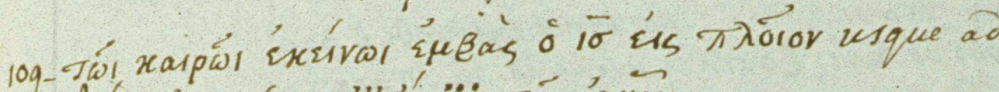

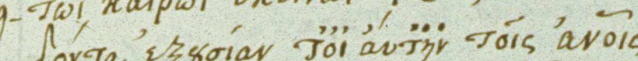

$$
\text { oakzáror לे }
$$

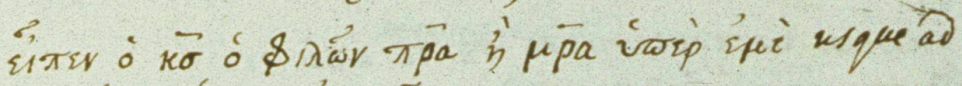

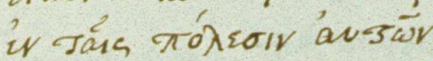

$$
\text { xupiaxy } \overline{3}
$$

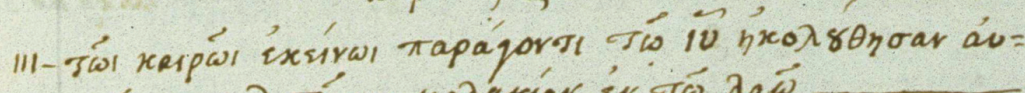
Math. 10.37 ad 16.1

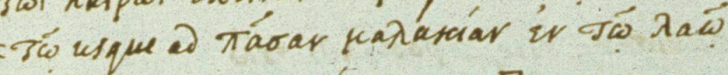

$$
\text { ókßasor } \bar{n}
$$

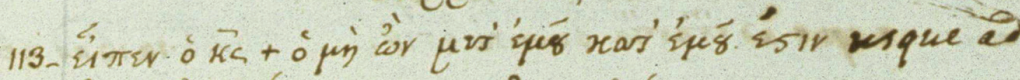

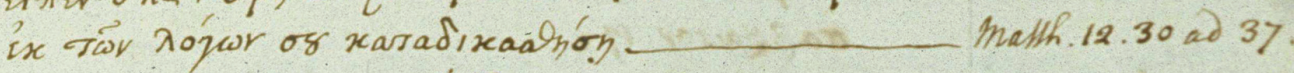

$$
\text { xupiaxín in }
$$

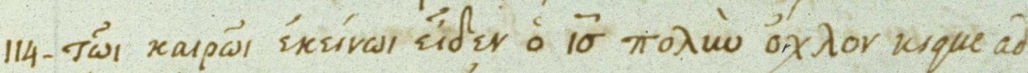

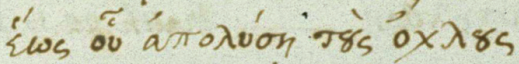
hath.14.14.2022.

$$
\text { бáßzaror } \vartheta
$$

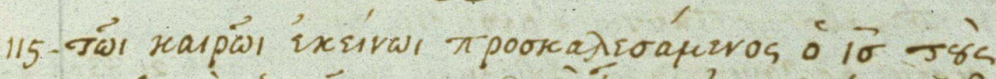

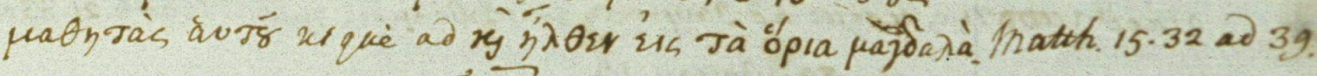
xupiaxen $\overrightarrow{9}$

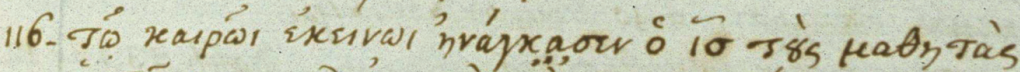

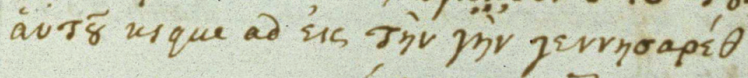

$$
\text { бáßßasor } \vec{i}
$$

Inath. 14.2220234

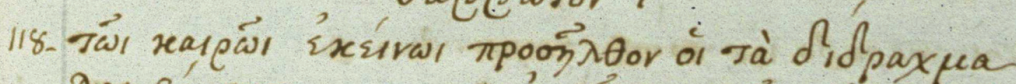

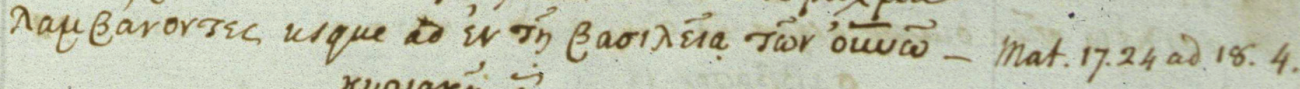

$$
\text { xupiaxén } \rightarrow
$$

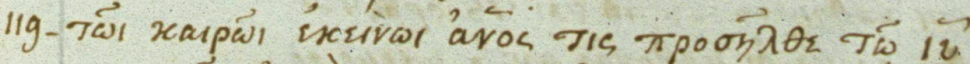

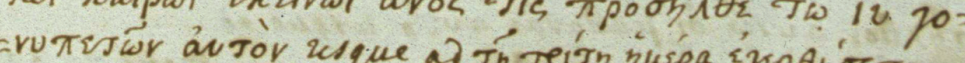

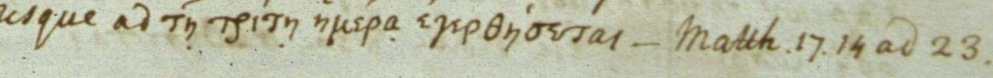

PI. 8: Toledo, ABC 31-31, p. 5: índice del códice elaborado por su poseedor, Thomas Wagstaffe 